\title{
GROWTH FACTORS AND OCULAR WOUND HEALING
}

\author{
GREGORY SCHULTZ ${ }^{1,2}$, PENG T. KHAW ${ }^{1}$, KAREN OXFORD ${ }^{2}$, SHAWN MACAULEY ${ }^{3}$, \\ GYSBERT VAN SETTEN $^{4}$ and NASSER CHEGINI ${ }^{1}$ \\ Gainesville, Florida, Stockholm, Sweden and London
}

\begin{abstract}
SUMMARY
Protein growth factors regulate many of the processes in vitro that are essential for the process of normal ocular wound healing, including migration, mitosis and differentiation of cells. This has led to the hypothesis that peptide growth factors play key roles in regulating normal ocular wound healing in vivo. A corollary to this concept is that insufficient action of growth factors causes impaired healing, and prolonged action of growth factors produces excessive scarring. If both of these concepts are correct, then the addition of exogenous protein growth factors should enhance healing of chronic ocular wounds and reducing prolonged actions of growth factors should limit excessive scarring. Although much remains to be understood about the role of growth factors in ocular development and wound healing, results of a substantial number of laboratory and clinical experiments indicate that these hypotheses are generally correct. This article reviews the results of pre-clinical experiments and clinical trials investigating the roles of protein growth factors in ocular development and wound healing.
\end{abstract}

\section{GROWTH FACTORS AFFECTING OCULAR CELLS}

The eye is a target tissue for peptide growth factors from all of the major families of growth factors: epidermal growth factor (EGF), fibroblasts growth factor (FGF), platelet-derived growth factor (PDGF), insulin-like growth factor (IGF), and transforming growth factor beta (TGFB) (see references in reviews by Bennett and Schultz ${ }^{1,2}$ and Schultz et al. $\left.{ }^{3,4}\right)$. The actions of two structurally similar proteins of the EGF family of proteins have been studied extensively in the cornea. EGF and transforming growth factor alpha (TGF $\alpha$ ) share substantial sequence homology (approximately 70\%), and both have

From: Departments of 'Obstetrics/Gynaecology, ${ }^{2}$ Ophthalmology, and ${ }^{3}$ Oral Biology, University of Florida, Gainesville, Florida, USA; ${ }^{4}$ Department of Ophthalmology, Karolinska University, Stockholm, Sweden; ${ }^{5}$ Moorfields Eye Hospital, Institute of Ophthalmology, London.

Correspondence to: Dr Gregory Schultz, Department of Obstetrics/ Gynaecology, Box 100294, University of Florida, Gainesville, FL 32610-0294, USA. Fax: (904) 392-6994. the triple disulphide-loop structure that is characteristic of this family of growth factors.

The proteins of the EGF family of growth factors stimulate cells by binding to and activating a receptor protein, commonly referred to as the EGF receptor.' All three major types of corneal cells (epithelial cells, fibroblasts and endothelial cells) express the EGF receptor, which is a 170000 molecular weight transmembrane glycoprotein. The extracellular region contains the growth factor binding domain, and the cytoplasmic portion of the receptor contains the tyrosine kinase domain. After binding a growth factor, EGF receptors rapidly dimerise, which activates the tyrosine kinase activity in the cytoplasmic region of the receptor. The activated EGF receptors then phosphorylate selected cellular proteins on tyrosine residues which activates these proteins. This initiates a cascade of events which are only partially understood but eventually result in migration, mitosis and differentiation of target cells.

\section{ROLE OF TGF $\alpha$ IN OCULAR DEVELOPMENT AND WOUND HEALING}

One technique for investigating the role of growth factors in development of the eye and in ocular wound healing is to prevent synthesis of the growth factor. Using homologous recombination in embryonic stem cells ('gene knock-out' technique), transgenic mice were created which do not synthesise TGF $\alpha^{5.6}$ A high percentage of mice lacking TGF $\alpha$ displayed ocular abnormalities of variable incidence and severity, including open eyelids at birth, reduced eyeball size and superficial opacity. Histological examination revealed eyelid and anterior segment dysgenesis, corneal inflammation and scarring, and lens and retinal defects. These results strongly indicate that TGF $\alpha$ production is required for normal development of the eye.

We previously reported that human tears contain both EGF and TGF $\alpha$ proteins and that the probable source is the lacrimal gland, on the basis of the presence of EGF and TGF $\alpha$ mRNAs and proteins in the tissue. ${ }^{7}$ Furthermore, human corneal epithelial cells contain TGF $\alpha$ mRNA and protein. ${ }^{8}$ This led us to speculate that EGF and TGF $\alpha$ pro-

Eye (1994) 8, 184-187 $\quad$ C 1994 Royal College of Ophthalmologists 
duced by epithelial cells might stimulate the normal turnover of corneal epithelial cells by an autocrine mechanism (Fig. 1). Furthermore, EGF and TGF $\alpha$ in tears might enhance healing of corneal surface wounds by an exocrine pathway. The results of the TGF $\alpha$ gene knock-out experiments support the concept that TGF $\alpha$ is necessary for normal development and maintenance of the corneal epithelium. However, healing of epithelial wounds created in the TGF $\alpha$ knock-out mice was not impaired. Thus, although TGF $\alpha$ was required for normal development and maintenance of the epithelium, it was not required for epithelial wound healing. It is possible that either EGF or TGF $\alpha$ alone is able to stimulate corneal epithelial wound healing, and that redundancy has developed in the EGF/ TGF $\alpha$ system for epithelial wound healing. Thus, loss of either EGF or TGF $\alpha$ synthesis would not lead to a totally non-functional EGF receptor system due to compensation by the other growth factor.

\section{TREATMENT OF OCULAR WOUNDS WITH GROWTH FACTORS}

Because peptide growth factors such as EGF stimulate mitosis, migration and differentiation of corneal cells in vitro, it was anticipated that treatment of corneal injuries with growth factors would significantly enhance healing. A large number of animal experiments have reported that addition of exogenous peptide growth factors stimulated ocular wound healing in animals. A limited number of clinical trials evaluating growth factors have been completed; the results are mixed, with four reports of acceleration of healing and two of no enhancement of healing (see references in reviews by Bennett and Schultz ${ }^{1,2}$ and Schultz et al. $^{3.4}$ ).

\section{Epithelial Wound Healing}

A substantial number of studies in rabbits and primates have reported that topical treatment with EGF enhanced healing rates of epithelial wounds. The epithelial wounds were created by a variety of techniques including mechanical scraping, mild chemical burns with iodine vapour, or solubilisation with organic solvents (octanol). EGF treatment has consistently accelerated the rate of epithelial regeneration from $25 \%$ to $45 \%$ in simple animal models.

EGF has also been evaluated in clinical trials of epidermal regeneration (see references in reviews by Bennett and Schultz ${ }^{1,2}$ and Schultz et al. ${ }^{3.4}$ ). Topical application of a high concentration of mouse EGF $(2 \mathrm{mg} / \mathrm{ml})$ significantly accelerated the rate of healing for 94 patients with a variety of ocular surface wounds or corneal ulcers. A multicentre, double-masked clinical trial evaluated the effects of recombinant EGF eye drops $(10 \mu \mathrm{g} / \mathrm{ml})$ on rates of healing for 104 patients with traumatic epithelial defects. Planimetric measurements of fluorescein-stained epithelial defect areas demonstrated that EGF treatment

\section{LACRIMAL GLAND}

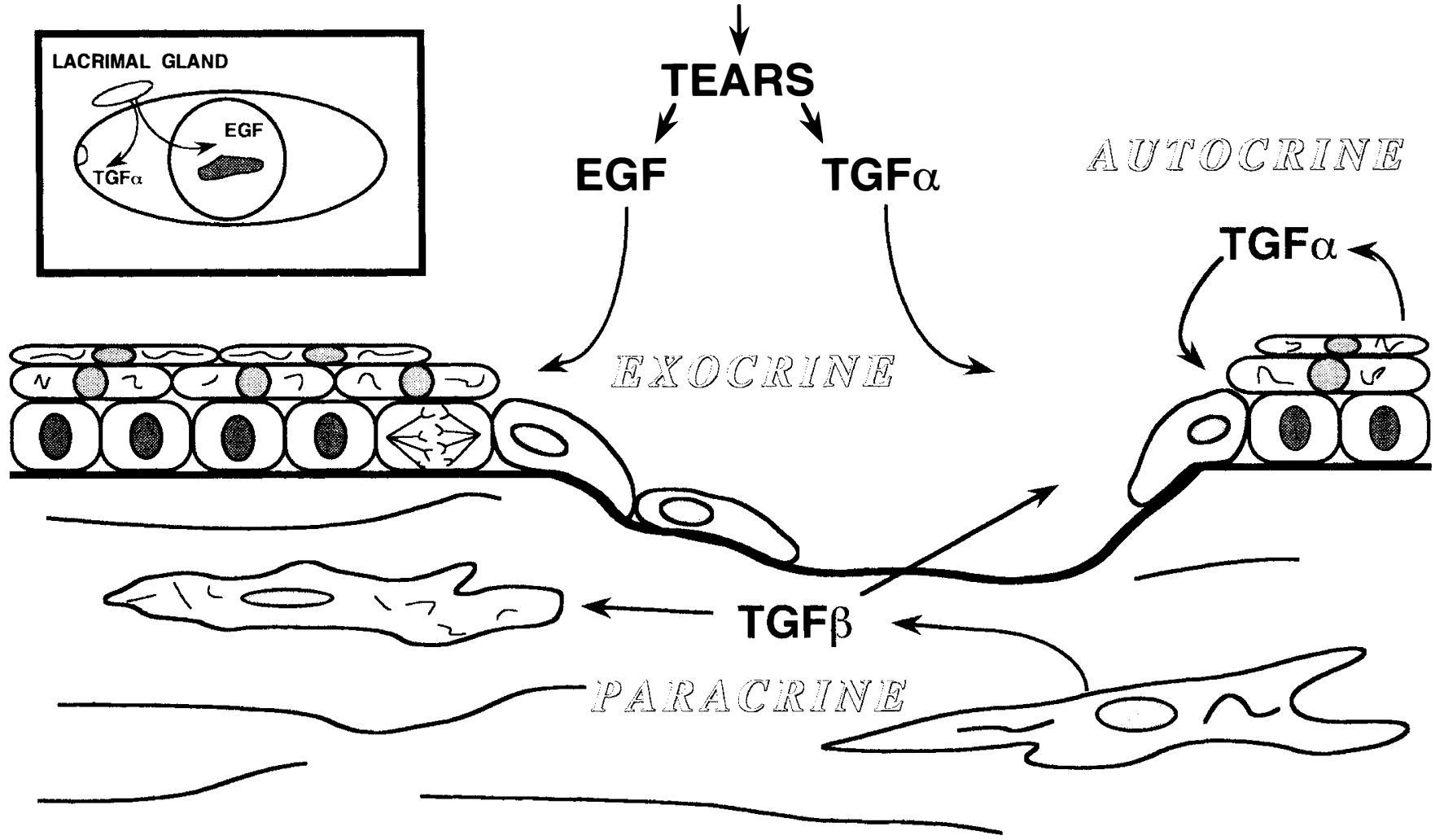

Fig. 1. Model of growth factor action in corneal wound healing. Protein growth factors appear to regulate spontaneous corneal wound healing by several pathways. Epidermal growth factor $(E G F)$ and transforming growth factor alpha $(T G F \alpha)$ synthesised in the lacrimal gland and secreted in tears can stimulate corneal cells by an exocrine pathway. Growth factors such as TGF $\alpha$ or TGF $\beta$ synthesised by corneal epithelial cells or stromal fibroblasts may act on the cells that synthesised the growthfactor(autocrine pathway) or on adjacent cells (paracrine pathway). 
significantly accelerated the rate of healing by approximately $30 \%$ compared with vehicle treatment. Another clinical trial of 35 patients following penetrating keratoplasty reported no effect of mouse EGF eye drops (1-2 $\mathrm{mg} / \mathrm{ml}$ ) on the rate of epithelial healing. In a similar trial, treatment of corneal transplant patients with bFGF at $100 \mu \mathrm{g} / \mathrm{ml}$ also did not accelerate the rate of corneal epidermal regeneration. ${ }^{9}$ Thus, neither EGF nor FGF treatment successfully enhanced epithelial healing in the clinical setting after corneal transplantation. It is possible that the combination of EGF or FGF with immune-suppressing drugs, which tend to impair healing, blunts the effect of the growth factors.

\section{Stromal Wound Healing}

Growth factors have also been reported to enhance stromal wound healing (see references in reviews by Bennett and Schultz ${ }^{2}$ and Schultz et al. $\left.{ }^{3,4}\right)$. Following an injury to the stroma, quiescent fibroblasts become activated and migrate to the site of injury where they proliferate and then synthesise extracellular matrix molecules such as collagen to form the scar. Topical application of EGF increased tensile strength of sutured or unsutured full-thickness incisions in rabbits and primates, even when healing was impaired by corticosteroids. The level of EGF applied is important in achieving an increase in tensile strength, with an optimum effect at $10 \mu \mathrm{g} / \mathrm{ml}$ and decreased tensile strength at higher doses $(1000 \mu \mathrm{g} / \mathrm{ml})$. The ability of EGF to increase tensile strength of corneal incisions is probably due to its ability chemotactically to stimulate migration and mitosis of stromal fibroblasts, which increases the total number of activated fibroblasts in the incision, rather than it causing an increase in the rate of collagen synthesis.

Recently, we reported that TGF $\beta$ increased the tensile strength of stromal incisions in rabbits when applied topically. ${ }^{10}$ The ability of TGF $\beta$ to increase tensile strength of corneal incisions is probably due to its ability chemotactically to increase the number of stromal fibroblasts in an incision and to increase synthesis of collagen and lysyl oxidase proteins by fibroblasts. TGF $\beta$ may also reduce synthesis of matrix metalloproteinases and increase synthesis of tissue inhibitors of metalloproteinases.

\section{Endothelial Wound Healing}

Endothelial wound healing in humans and primates occurs primarily by migration and enlargement of uninjured cells surrounding the wound area (see references in reviews by Bennett and Schultz ${ }^{2}$ and Schultz et al. ${ }^{3.4}$ ). Mitosis occurs only rarely. In contrast, endothelial cells of rabbit corneas undergo mitosis extensively after wounding. Cat endothelial cells also respond to endothelial wounding by limited mitosis and, therefore, cats have been used as an animal model for human endothelial wound healing. Several studies have investigated the changes which occur in the aqueous humour of cats after the creation of an endothelial wound and the effects of exogenous growth factors on endothelial wound healing. It is generally accepted that primary aqueous humour from humans or cats contains low levels of proteins and has minimal mitogenic activity. Recently, we reported that primary aqueous humour collected from cats prior to creating a central touch injury to the endothelium contained low levels of TGF $\alpha$ immunoreactive protein $(7 \mathrm{ng} / \mathrm{ml})$, and that the concentration of TGF $\alpha$ increased 12-fold (97 ng/ml) 2 hours after wounding then progressively decreased to pre-wounding levels by 24 hours. " No increase in mitogenic activity or TGF $\alpha$ concentration was found in secondary aqueous from sham-injured eyes, suggesting that the endothelial injury increased the concentration of TGF $\alpha$ in the aqueous humour.

The effects of addition of exogenous EGF to the anterior chamber of cats have been studied rather extensively. EGF injected into the anterior chamber of rabbits was rapidly cleared from the aqueous humour with a halflife of approximately 0.6 hours. A single injection of EGF into the anterior chamber of cats after a transcorneal freeze injury increased the rate of endothelial wound closure only when EGF was delivered in a specific viscoelastic material: sodium hyaluronidate. EGF delivered in saline or methylcellulose was ineffective in accelerating endothelial wound closure. Similarly, no difference in corneal thickness or central corneal endothelial cell density was found in cryo-injured cat corneas treated with water alone or water containing EGF. However, we recently reported that EGF delivered in sodium hyaluronate significantly enhanced several key parameters of endothelial wound healing including mitosis, endothelial cell density, percentage of hexagonal cells, and polymegethesim. ${ }^{12}$ These results suggest that exogenous growth factors such as EGF can enhance endothelial wound healing provided their residency time in the anterior chamber is sufficient to enable their effects to occur.

\section{FUTURE INVESTIGATIONS OF GROWTH FACTORS AND OCULAR WOUND HEALING}

Another important area for future investigation is the potential synergistic effects between EGF or TGF $\alpha$ and agents such as protease inhibitors or extracellular matrix proteins. Severe corneal injuries such as alkali burns or bacterial infections often overwhelm the endogenous ability of the cornea to heal these types of wounds spontaneously. We recently reported that a combination of EGF, fibronectin (a cell attachment protein), aprotinin (a serine protease inhibitor) and Galardin (a synthetic inhibitor of matrix metalloproteinases) was very effective in blocking ulceration and promoting epithelial regeneration for up to 4 weeks after alkali injury to rabbit corneas. ${ }^{13}$ Neither EGF, fibronectin or Galardin alone, nor the combination of EGF plus fibronectin, were effective in controlling ulceration and promoting epithelial regeneration. Thus, strategies for treatment of severe corneal injuries should consider the total environment of a corneal wound and utilise multiple agents which can each correct a different aspect of the wound environment. For example, wounds 
with a denatured extracellular matrix will need factors to enhance cell migration and attachment while wounds with excess protease activity will need specific inhibitors to allow the wound cells to regenerate receptors for growth factors and extracellular matrix components.

Substantial progress has been made in understanding healing of ocular wounds at the molecular level, but many important questions remain unanswered. It will be important to characterise further the roles of peptide growth factors, their receptors, extracellular matrix proteins and proteases in the process of normal ocular wound healing. Once this baseline of fundamental data is known, it will be necessary to contrast the molecular environment of spontaneously healing ocular wounds with the environment of chronic ocular ulcers with respect to levels of growth factors, proteases and growth inhibitory agents. Better combinations of agents can then be rationally designed to correct deficiencies that have been identified in the environment of chronic corneal wounds. Obtaining answers to these questions will be difficult but the knowledge should greatly improve the ability clinically to control healing of ocular wounds.

Supported in part by funds from NIH grant EY05587, Oxford Congress Scholarship and the Wellcome Trust, London.

Key words: EGF, Growth factors, Protease inhibitors, TGF $\alpha$, Wound healing.

\section{REFERENCES}

1. Bennett NT, Schultz GS. Growth factors and wound healing. I. Biochemical properties of growth factors and their receptors. Am J Surg 1993;165:728-37.

2. Bennett NT, Schultz GS. Growth factors and wound healing. II. Role in normal and chronic wound healing. Am J Surg $1993 ; 166: 74-81$.
3. Schultz GS, Rotatori DS, Clark W. EGF and TGF $\alpha$ in wound healing and repair. J Cell Biochem 1991;45:364-52.

4. Schultz GS, Chegini N, Grant M, Khaw PT, MacKay SLD. Effect of growth factors on corneal wound healing. Acta Ophthalmol (Copenh) 1992;70:60-6.

5. Luetteke NC, Qui TH, Peiffer RL, Oliver S, Lee DC. TGF $\alpha$ deficiency results in hair follicle and eye abnormalities in targeted and waved-1 mice. Cell 1993;73:263-78.

6. Mann GB, Fowler KJ, Gabriel A, Nice EC, Williams RL, Dunn AR. Mice with a null mutation of the TGF $\alpha$ gene have abnormal skin architecture, wavy hair, and curly whiskers and often develop corneal inflammation. Cell 1993;73: 249-61.

7. van Setten GB, Macauley S, Schultz GS. TGFo: presence in human tear fluid and in lacrimal gland tissue. Invest Ophthalmol Vis Sci 1993;34(Suppl):822.

8. Khaw PT, Schultz GS, MacKay SLD, Chegini N, Adams J, Shimizu R. Human corneal epithelium : autocrine production of TGF $\alpha$ mRNA and protein. Invest Ophthalmol Vis Sci 1992;33:3302-6.

9. Assouline A, Lamrani A, Abenhaim A, Danel P, Mignard D, Rieck $\mathrm{P}$, et al. Prospective randomised trial of basic fibroblast growth factor in penetrating keratoplasty (PKP) in humans. Invest Ophthalmol Vis Sci 1993;34(Suppl):1374.

10. Oxford KW, Balch KC, Schutz GS, van Setten GB, Stern GA. Effects of TGF $\beta$ on the re-epithelialisation and tensile strength of corneal wounds. Invest Ophthalmol Vis Sci 1993;34(Suppl): 1375.

11. Rotatori DS, Kerr NC, Raphael B, McLaughlin BJ, Shimizu R, Stern GA, Schultz GS. Elevation of TGF $\alpha$ in aqueous humour of cats after endothelial injury. Invest Ophthalmol Vis Sci 1993;35:143-9.

12. Raphael B, Kerr NC, Shimizu RW, Lass JH, Crouthamel $\mathrm{KC}$, Glaser SR, et al. Enhanced healing of cat endothelial wounds by EGF. Invest Ophthalmol Vis Sci 1993;34: 2305-12.

13. Schultz GS, Strelow S, Stern GA, Chegini N, Grant MB, Galardy RE et al. Inhibition of corneal ulceration following severe alkali injury by a synthetic metalloproteinase inhibitor. Invest Ophthalmol Vis Sci 1992;33:3325-31. 